\title{
A study of preoperative factors associated with a poor outcome following laparoscopic bile duct exploration
}

\author{
Ragini Kilambi • Virinder Kumar Bansal • \\ Mahesh C. Misra
}

Published online: 26 October 2010

(C) Springer Science+Business Media, LLC 2010

The authors' study on the preoperative factors associated with a poor outcome after laparoscopic bile duct exploration made an interesting read [1]. It seems to have been proven beyond doubt that laparoscopic bile duct exploration is more efficient and as safe as endoscopic sphincterotomy in young patients fit for GA. However, its efficiency and safety in the elderly age group and those with comorbidities remains debatable. It is interesting to note that your own study had brought out that laparoscopic CBD exploration is equally safe in the elderly [2].

Furthermore, this study has brought out certain relevant facts regarding the influence of the learning curve. However, it is not clear as to what exactly is meant by the learning curve and until what number of cases do the authors feel they are still inexperienced especially in the context of laparoscopic CBD exploration. Also no mention has been made of the operative time-a factor known to be significantly affected by the learning curveand how it has correlated with patient outcome. We in our limited experience of approximately 90 cases are in concurrence with your observation that learning curve does not influence the complication rate, although it may affect the conversion rate.

In your study, bile leak was the most common complication, occurring in $15.6 \%$ of patients. We have reported a transient bile leak of $13.3 \%$ in our study [3]. It would be interesting to know the authors' comments about the possible causes of bile leak. In our opinion, minor bile leaks are associated with a large number of laparoscopic CBD explorations done by choledochotomy due to spasm of lower end of the CBD probably due to instrumentation.

Disclosures Drs. Ragini Kilambi, Virinder Kumar Bansal, and Mahesh C. Misra have no conflicts of interest or financial ties to disclose.

\section{References}

1. Noble H, Whitley E, Norton S, Thompson M (2010) A study of preoperative factors associated with a poor outcome following laparoscopic bile duct exploration. Surg Endosc [Epub 22 June 2010]. doi:10.1007/s00464-010-1146-3

2. Noble H, Tranter S, Chesworth T, Norton S, Thompson M (2009) A randomised, clinical trial to compare endoscopic sphincterotomy and subsequent laparoscopic cholecystectomy with primary laparoscopic bile duct exploration during cholecystectomy in higher risk patients with choledocholithiasis. J Laparoendosc Adv Surg Tech A 19(6):713-720

3. Bansal VK, Misra MC, Garg P, Prabhu M (2010) A prospective randomized trial comparing two-stage versus single-stage management of patients with gallstone disease and common bile duct stones. Surg Endosc 24:1986-1989
R. Kilambi · V. K. Bansal ( ()$\cdot$ M. C. Misra Department of Surgical Disciplines, All India Institute of Medical Sciences, Room No. 5021, 5th Floor, Teaching Block, Ansari Nagar, New Delhi 110029, India

e-mail: drvkbansal@gmail.com 